\title{
KORELASI BERATNYA KEBIASAAN MEROKOK DENGAN DERAJAT GANGGUAN OBSESIF KOMPULSIF MEROKOK PADA MAHASISWA UNIVERSITAS MUHAMMADIYAH MALANG
}

\author{
Muhammad Khairul Afif', Isbandyah ${ }^{2}$, Iwan Sis Indrawanto ${ }^{3}$ \\ Fakultas Kedokteran Universitas Muhammadiyah Malang, J1. Bendungan Sutami No. 188A, Kota Malang, \\ 65145, Indonesia, (0341)551149
}

\begin{abstract}
ABSTRAK
Korelasi Beratnya kebiasaan merokok Dengan Derajat Gangguan Obsesif Kompulsif Merokok Pada Mahasiswa Universitas Muhammadiyah Malang. Latar Belakang: Kebiasaan merokok merupakan perilaku yang menyenangkan dan bergeser menjadi aktivitas yang bersifat obsesif. Kelainan pada sistem saraf yang menjembatani kontrol perilaku menyebabkan kebiasaan merokok menjadi suatu gangguan obsesif kompulsif merokok. Tujuan: Mengetahui korelasi antara beratnya kebiasaan merokok dengan derajat gangguan obsesif kompulsif merokok pada Mahasiswa Universitas Muhammadiyah Malang. Metode: Observasi analitik dengan pendekatan secara cross-sectional Study, dengan pengambilan data secara cluster sampling, dan besar sampel sebanyak 100 responden mahasiswa Fakultas Teknik UMM. Analisa data dengan menggunakan statistik uji korelasi Spearman dengan $=0.05$. Hasil Penelitian: Dari 100 orang sampel, jumlah terbanyak yang ditemukan adalah perokok ringan yaitu sebanyak 50 orang (50\%), dan lebih banyak yang mengalami gangguan obsesif kompulsif merokok dalam skala ringan yaitu sebanyak 46 orang (46\%). Hasil analisis didapatkan Koefisien korelasi $=+0.596$ dan p-value $<0,05$. Kesimpulan: Terdapat hubungan yang bermakna antara beratnya kebiasaan merokok dengan derajat gangguan obsesif kompulsif merokok. Dimana semakin berat kebiasaan merokoknya maka akan semakin berat derajat gangguan obsesif kompulsif merokok orang tersebut.
\end{abstract}

ABSTRACT
The Correlation Between the Degree of Smoking Habit and the Severeness of Obsessive Compulsive Smoking Disorder in College Student of Muhammadiyah Malang University. Background: Smoking habit is pleasant behavior and gradually can be shifted into an obsessive thinking activity. Abnormality in the nervous system that mediates the control of behavior causes the smoking habits became a obsessive compulsive smoking disorder. Objective: To find out the correlation between the degree of smoking and the severeness of obsessive compulsive smoking disorder. Method: : This study used analytic observation with crosssectional approach. Sample was obtained by cluster sampling method. The sample was 100 male Engineering Faculty student of Muhammadiyah Malang University. This study Analyzed with Spearman correlation test with $=0.05$. Result: Out of 100 sample, the bighest number was found have mild smoking habits with 50 students (50\%), and have an obsessive compulsive smoking in mild scale with 46 students $(46 \%)$. The analysis result of correlation coefficient was +0.596 with the $p<0,05$. Conclusion: : There was significant correlation between the degree of smoking habits and the more severe of obsessive compulsive smoking disorder. The heavier the smoking habit, the severeness the obsessive compulsive smoking disorder.

Key words: Nutritional status, Gross motoric development, Under five's children

\section{PENDAHULUAN}

Menurut hasil survey dari WHO, sepertiga penduduk di dunia terutama pada populasi dewasa adalah perokok. Indonesia merupakan konsumen rokok tertinggi kelima di dunia dengan jumlah rokok yang di konsumsi sekitar 215 miliar batang per tahun. Pada tahun 2004 34,5\% dari jumlah penduduk Indonesia adalah perokok, menunjukkan lebih dari 60 juta penduduk Indonesia adalah perokok (Tjandra, 2006). Smet (1998) mengatakan bahwa usia pertama kali merokok pada umumnya berkisar pada usia 11- 13 tahun dan mereka pada umumnya merokok sebelum usia 18 tahun (Irawan,2009). Kebiasaan merokok merupakan perilaku yang menyenangkan dan bergeser menjadi aktivitas yang bersifat obsesif. WHO menggolongkan kebiasan merokok sebagai suatu ketagihan. Selain menjadi ketagihan secara fisiologis, merokok juga memenuhi hasrat psikologis yang dirasakan. Proses menyalakan rokok dan menghembuskannya secara berulang-ulang menjadikan merokok sebagai suatu yang amat kompulsif (Dian,2006).

Gangguan obsesif kompulsif ditandai dengan pikiran yang mengganggu (obsesif), yang dapat meningkatkan kecemasan, dan kebiasaan yang berulang (kompulsif) yang dapat menurunkan kecemasannya (Stein, 2003). Prevalensi gangguan obsesif kompulsif pada populasi penduduk umum adalah 2-5\% (Stein,2002). Teori tentang penggunaan rokok menjadi gangguan obsesif kompulsif masih kurang dipahami. Kelainan pada sistem saraf yang menjembatani kontrol perilaku meyebabkan kebiasaan merokok menjadi suatu gangguan obsesif kompulsif. Selain 
itu stimuli yang dibiasakan dalam hal ini adalah kebiasaan merokok yang berulang juga dapat menyebakan gangguan obsesif kompulsif merokok (Brian, 2010). Kebiasaan merokok masih didominasi oleh para laki-laki. Ini dibuktikan dengan 24,5\% pelajar laki-laki di Indonesia adalah perokok, jauh lebih tinggi dibandingkan dengan pelajar wanita yang hanya 2,3\% (Tjandra et al., 2006). Dari total 4081 mahasiswa di Fakultas Teknik Universitas Muhammadiyah Malang mayoritas adalah mahasiswa laki-laki dengan presentase sebesar 84,2 \% (3436 mahasiswa). Berdasarkan uraian di atas penulis merasa tertarik untuk mengetahui hubungan kebiasaan merokok dengan gangguan obsesif kompulsif merokok pada Mahasiswa Fakultas Teknik Universitas Muhammadiyah Malang.

Tujuan penelitian ini bertujuan untuk mengetahui adanya korelasi antara beratnya kebiasaan merokok dengan derajat gangguan obsesif kompulsif merokok. Tujuan khusus penelitian ini untuk mengetahui distribusi derajat kebiasaan merokok pada mahasiswa Universitas Muhammadiyah Malang. Tujuan lainnya adalah untuk mengetahui distribusi derajat gangguan obsesif kompulsif merokok pada mahasiswa Universitas Muhammadiyah Malang. Manfaat Penelitian ini untuk mengetahui bahwa faktor kebiasaan merokok mendasari gangguan obsesif kompulsif merokok sehingga diperlukan intervensi psikiatri untuk menanggulanginya. Manfaat Akademik dapat digunakan sebagai salah satu dasar penelitian lebih lanjut terutama tentang hubungan antara kebiasaan merokok dengan gangguan obsesif kompulsif. Manfaat Masyarakat adalah menyadarkan masyarakat bahwa kebiasaan merokok mendasari gangguan obsesif kompulsif sehingga perlu pemeriksaan dini.

\section{METODE PENELITIAN}

Desain penelitian yang digunakan adalah observasional analitik dengan menggunakan rancangan penelitian metode Cross Sectional Study. Lokasi penelitian dilakukan di Universitas Muhammadiyah Malang pada tanggal 20 - 24 Maret 2012. Populasi target dari penelitian ini adalah mahasiswa di seluruh Universitas di Indonesia. Sedangkan populasi terjangkau adalah Mahasiswa Universitas Muhammadiyah Malang angkatan 2008-2011. Sampel yang digunakan dalam penelitian ini adalah mahasiswa laki-laki Fakultas Teknik Universitas Muhammadiyah Malang, yang memenuhi kriteria inklusi. Untuk menentukan besar sampel dengan tingkat ketepatan absolut yang dikehendaki sebesar $10 \%$, maka perkiraan besar sampel yang digunakan adalah 98 orang. Pengambilan sampel yang digunakan adalah dengan cluster sampling.

Karakteristik sampel penelitian ditentukan berdasarkan kriteria inklusi dan kriteria eksklusi. Kriteria inklusi penelitian ini adalah mahasiswa laki-laki Fakultas Teknik UMM yang merokok/ Kriteria eksklusi penelitian ini adalah mahasiswa yang telah terdiagnosa menderita gangguan obsesif kompulsif sebelum mempunyai kebiasaan merokok. Selanjutnya, mahasiswa yang mempunyai masalah psikososial yang serius. Begitu juga dengan mahasiswa yang tidak bersedia terlibat dalam penelitian.
Definisi Yale-Brown Obsessive Compulsive Scale pada penelitian ini adalah skala yang digunakan untuk mengetahui apakah orang tersebut mengalami gangguan obsesif kompulsif atau tidak. Derajat gangguan obsesif kompulsif menurut Yale-Brown Obsessive Compulsive Scale adalah : Skor 07 yaitu gangguan obsesif kompulsif subklinik. Skor 8-15 yaitu gangguan obsesif kompulsif ringan. Skor 16-23 yaitu gangguan obsesif kompulsif sedang. Skor 24-31yaitu gangguan obsesif kompulsif berat. Skor 32-40 yaitu gangguan obsesif kompulsif sangat berat. Kebiasaan merokok adalah seseorang yang merokok minimal 1 batang rokok per hari. Dengan derajat ketergantungan berdasarkan Fagerstrom Test for Nicotine Dependence adalah sebagai berikut : skor $<5$ : perokok ringan ; skor 5-7 : perokok sedang ; skor $>7$ : perokok berat/ Gangguan Obsesif Kompulsif Merokok adalah gangguan dimana individu mempunyai pikiran tentang rokok yang menetap dan berulang yang sangat mengganggu dan dapat menyebabkan kecemasan atau distress (obsesi). Kemudian untuk mengurangi kecemasannya individu tersebut melakukan aktivitas berulang (kompulsi) dimana kompulsi disini berupa kebiasaan merokok. Tingkatan gangguan obsesif kompulsif merokok menurut Obsessive Compulsive Smoking Scale (OCSS) dengan tingkatan: Skor 07 yaitu gangguan obsesif kompulsif merokok subklinik. Skor 8-15 yaitu gangguan obsesif kompulsif merokok ringan. Skor 16-23 yaitu gangguan obsesif kompulsif merokok sedang. Skor 24-31 : gangguan obsesif kompulsif merokok berat. Skor 32-40 yaitu gangguan obsesif kompulsif merokok sangat berat. Masalah psikososial adalah masalah psikis dan sosial yang dialami seseorang yang dapat menimbulkan hendaya dalam kehidupan seharihari. Contohnya adalah masalah dengan hukum, keluarga, sahabat atau akademik. Dalam penelitian ini akan ditanyakan dalam kuesioner untuk mengetahui apakah sampel sedang mengalami masalah psikososial atau tidak. Jika sedang mengalami masalah psikososial serius maka akan termasuk kriteria eksklusi.

Instrumen penelitian ini adalah menggunakan beberapa lembar kuesioner. Pertama, lembar kuesioner Yale-Brown Obsessive Compulsive Scale (Y-BOCS), untuk menentukan apakah sampel sudah menderita gangguan obsesif kompulsif sebelumnya atau tidak. Kedua, lembar kuesioner Fagerstrom Test for Nicotine Dependenc untuk mengukur derajat ketergantungan merokok. Ketiga, lembar kuesioner OCSS untuk mengukur derajat gangguan obsesif kompulsif. Suatu alat ukur dapat dinyatakan sebagai alat ukur yang baik dan mampu memberikan informasi yang jelas dan akurat apabila telah memenuhi beberapa kriteria yang telah ditentukan oleh para ahli psikometri, yaitu kriteria valid dan reliabel. Oleh karena itu agar kesimpulan tidak salah dan tidak memberikan gambaran yang jauh berbeda dari keadaan yang sebenarnya diperlukan uji validitas dan reliabilitas dari alat ukur yang digunakan dalam penelitian.

Uji Validitas dan reliabilitas dilakukan pada penelitian ini. Menurut Sutanto Priyo Hastono (2007), Validitas adalah seberapa jauh ketepatan suatu alat ukur dalam mengukur suatu data. Suatu alat ukur dapat dikatakan mempunyai validitas tinggi apabila alat ukur tersebut menjalankan 
fungsi ukurnya atau memberikan hasil ukur yang sesuai dengan maksud dilakukannya pengukuran tersebut. Pengujian validitas dilakukan dengan menggunakan korelasi Pearson Product Moment. Hasil korelasi (r) Pearson digunakan untuk mendeteksi masing-masing item pertanyaan. Item pertanyaan dinyatakan valid jika nilai (r) Pearson lebih besar dari nilai kritis pada tabel (r) Product Moment korelasi pearson sesuai dengan derajat kebebasan dan signifikasinya. Reliabilitas adalah suatu ukuran yang menunjukkan sejauh mana hasil pengukuran tetap konsisten bila dilakukan pengukuran dua kali atau lebih terhadap gejala yang sama dan dengan alat ukur yang sama (Hastono, 2007). Dari hasil uji validitas, item pertanyaan yang dinyatakan valid diukur reliabilitasnya dengan bantuan program SPSS for windows. Menurut Sugyono (2007), suatu alat ukur dinyatakan memiliki reliabilitas tinggi atau dapat dipercaya, jika alat tersebut mantap. Dapat diartikan bahwa alat tersebut stabil, dapat diandalkan (Dependability) dan dapat juga diramalkan (Predictability). Uji reliabilitas didasarkan pada nilai Alpha Cronbach (á), jika nilai Alpha Cronbach (á) lebih besar dari nilai kritis pada tabel (r) Product Moment maka data penelitian dianggap cukup baik dan reliabel untuk digunakan sebagai input dalam proses penganalisaan data guna menguji hipotesis penelitian (Sugyono, 2007).

Alur Penelitian ini adalah awal penelitian menghitung jumlah sampel yang akan dilakukan penelitian. Setelah itu diadakan wawancara terhadap sampel sesuai dengan kuesioner Yale-Brown Obsessive Compulsive Scale untuk menentukan apakah sampel menderita gangguan obsesif kompulsif secara umum atau tidak. Jika ternyata sampel menderita gangguan obsesif kompulsif secara umum sebelum mempunyai kebiasaan merokok maka sampel tersebut dieksklusikan. Selain itu di kuesioner diberikan pertanyaan apakah sampel sedang mengalami masalah serius yang berhubungan dengan hukum, keluarga, sahabat atau akademik. Jika mempunyai sampel sedang punya masalah tersebut maka akan dieksklusikan, Kemudian sampel yang memenuhi kriteria inklusi akan diberi kuesioner Fagerstrom Test for Nicotine Dependence dan Obsessive Compulsive Smoking Scale untuk menentukan tingkat ketergantungan kebiasaan merokok dan derajat gangguan obsesif kompulsif merokok. Setelah semua data terkumpul lalu dilakukan analisis data untuk mengetahui korelasi beratnya kebiasaan merokok dengan gangguan obsesif kompulsif merokok. Analisis Data yang didapat akan disajikan dalam bentuk tabel. Kemudian dilakukan uji statistik menggunakan uji korelasi Rank Spearman dengan bantuan program komputer SPSS for windows. Taraf signifikasi yang digunakan adalah $95 \%$ atau taraf kesalahan $0,05 \%$.

\section{HASIL DAN PEMBAHASAN}

Penelitian ini dilakukan untuk menggambarkan dan mengetahui adanya korelasi antara kebiasaan merokok dengan gangguan obsesif kompulsif merokok pada Mahasiswa Universitas Muhammadiyah Malang. Sampel yang digunakan dalam penelitian ini adalah mahasiswa laki-laki Fakultas Teknik Universitas Muhammadiyah Malang, sesuai dengan kriteria yang telah ditentukan dan diperoleh 100 orang sampel yang bersedia menjadi responden dalam penelitian ini. Hasil penelitian tentang kebiasaan merokok dengan derajat ketergantungan berdasarkan Fagerstrom Test for Nicotine Dependence pada mahasiswa laki-laki Fakultas Teknik Universitas Muhammadiyah Malang menunjukkan bahwa kebanyakan dari mereka termasuk dalam kategori perokok ringan $(50 \%)$. Hal ini sesuai dengan penelitian terdahulu yang menyatakan bahwa berat kebiasaan merokok pada mahasiswa masih tergolong ringan (Rak, 2010). Rata-rata anak-anak dan remaja terutama mahasiswa perokok ringan. Hal ini disebabkan kalangan mahasiswa merupakan kelompok yang sensitive terhadap tingginya harga rokok. Jadi tingkat konsumsi merokok pada mahasiswa belum mencapai angka yang sangat parah (Jha \& Chaloupka, 2000).

Mahasiswa laki-laki Fakultas Teknik Universitas Muhammadiyah Malang yang menjadi responden dalam penelitian ini lebih banyak yang mengalami gangguan obsesif kompulsif merokok dalam skala yang ringan. Hal ini dapat dimaknai bahwa para mahasiswa tersebut mengalami pikiran atau perasaan yang tidak dapat dihilangkan dengan usaha apapun secara logika, yang disertai dengan kecemasan akibat merokok yang masih dalam kategori ringan. Namun demikian, kondisi ini harus segera diatasi, sebelum kemudian menjadi semakin parah menjadi gangguan obsesif kompulsif merokok yang lebih berat. Hasil ini berbanding lurus dengan beratnya kebiasaan merokok. Dimana semakin rendah kebiasaan merokok maka derajat gangguan obsesif kompulsif merokoknya juga ringan. Pada hasil wawancara ditemukan mengapa mereka hanya mengalami gangguan obsesif kompulsif merokok ringan karena perhatian mereka akan rokok masih dapat dialihkan dengan kegiatan-kegiatan lain seperti organisasi kemahasiswaan, belajar kelompok, dan aktifitas lain seperti olahraga. Selain itu mereka juga merasa segan untuk merokok karena masih banyak diantara teman-teman mereka yang tidak merokok jadi mereka masih dapat untuk menahan keinginan mereka untuk tidak merokok.

Hasil penelitian menunjukkan bahwa beratnya kebiasaan merokok berbanding lurus dengan derajat gangguan obsesif kompulsif merokok. Namun masih ada kejanggalan dimana pada perokok ringan ditemukan mempunyai gangguan obsesif kompulsif merokok yang berat sebanyak 3 orang. Hal ini disebabkan karena peneliti menemukan beberapa faktor perancu yang tidak bisa disingkirkan karena adanya keterbatasan waktu. Faktor perancu tersebut antara lain adalah faktor biologis (keturunan), faktor psikososial (kesibukan/pekerjaan), dan kemungkinan gangguan kecemasan (anxiety disorder). Namun secara statistika beratnya kebiasaan merokok dan derajat kebiasaan merokok masih mempunyai hubungan yang signifikan karena pada hasil uji korelasi spearman didapatkan koefisien korelasinya adalah +0.596 dengan nilai signifikansi $(\mathrm{p})<0.05$. Hasil penelitian ini sesuai dengan penelitian terdahulu bahwa semakin besar angka ketergantungan merokok maka akan diikuti dengan semakin berat derajat gangguan obsesif kompulsif merokok, demikian juga sebaliknya. Hal ini disebabkan bahwa kelainan pada sistem saraf yang menjembatani kontrol perilaku (contohnya orbitofrontal dan limbic region) meyebabkan kebiasaan merokok menjadi suatu obsesif kompulsif. Selain itu stimuli yang dibiasakan dalam hal ini adalah kebiasaan merokok yang berulang juga dapat menyebakan gangguan obsesif kompulsif merokok (Brian, 2010). 
Gangguan obsesif kompulsif merokok dapat disebabkan karena faktor tingkah laku. Ketika seseorang menyadari bahwa perbuatan tertentu dapat mengurangi kecemasan akibat obsesif, orang tersebut mengembangkan suatu strategi penghindaran aktif dalam bentuk kompulsi atau ritual untuk mengendalikan kecemasan tersebut. Secara perlahan, karena efikasinya dalam mengurangi kecemasan, strategi penghindaran ini menjadi suatu pola tetap dalam kompulsi. Hal ini menjelaskan bahwa perilaku merokok yang menetap dan berulang dapat menjadi sebuah gangguan obsesif kompulsif merokok. Beratnya kebiasaan merokok berbanding lurus dengan beratnya gangguan obsesif kompulsif merokok pada orang tersebut. (Kaplan ,2010).

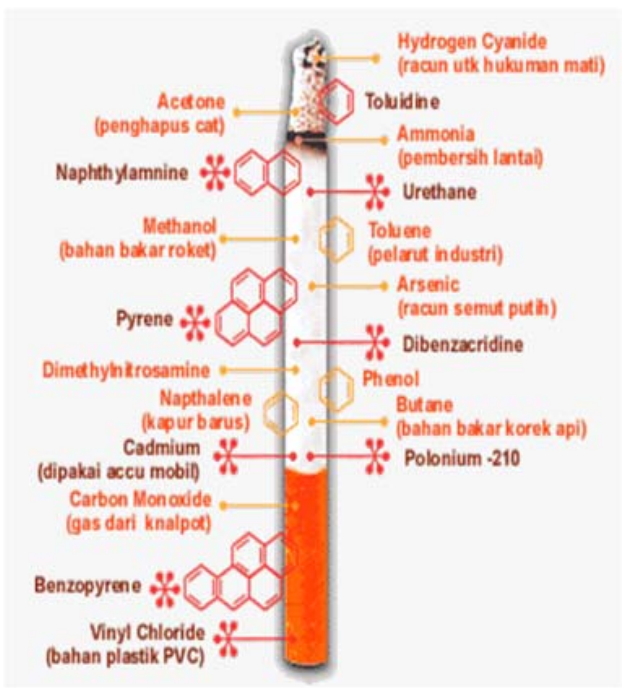

Gambar 1. Kandungan Rokok

(http://Jurnal-ilmiahkedokteran_ property. com/2007/ 11294/jhshulqw/)

Banyak penelitian yang mendukung adanya hipotesis bahwa disregulasi serotonin berpengaruh pada pembentukan gejala gangguan obsesif - kompulsif. Pada penderita gangguan obsesif kompulsif serotonin dalam otak menurun. Tetapi serotonin sebagai penyebab gangguan obsesif kompulsif masih belum jelas. Genetik juga diduga berpengaruh untuk terjadinya gangguan obsesif - kompulsif dimana ditemukan perbedaan yang bermakna antara kembar monozigot dan dizigot (Kaplan, 2010).

Prevalensi seumur hidup gangguan obsesif kompulsif pada populasi umum diperkirakan adalah 2-3\%. Beberapa peneliti telah memperkirakan bahwa gangguan obsesif kompulsif ditemukan pada sebanyak $10 \%$ pasien rawat jalan di klinik psikiatrik. Angka tersebut menyebabkan gangguan obsesif kompulsif sebagai diagnosis tersering yang keempat setelah fobia, gangguan berhubungan zat, dan gangguan depresif berat (Kaplan, 2010).

Gangguan obsesif kompulsif tidak mengenal batas usia, gangguan psikiatri ini dapat ditemukan pada anakanak maupun dewasa (Heyman, 2006). Untuk orang dewasa, jenis kelamin tidak berpengaruh, karena jumlah penderita laki-laki dan penderita perempuan sama banyaknya (Taylor, 2009).

Nikotin sebagai hasil dari proses merokok mempunyai efek memberikan rasa yang lebih tenang, daya pikir serasa lebih cemerlang, memacu sistem dopaminergik dan mampu menekan rasa lapar. Efek dari nikotin berlangsung sebentar saja, oleh karena itu perokok harus terus merokok guna mempertahankan efek sensasi dari nikotin dan untuk menghindar dari gejala putus nikotin. Tetapi bila kadar nikotin turun di dalam darah, perokok akan merasa gelisah, tidak dapat tenang, ini disebut gejala putus nikotin. Sementara di jalur adrenergik, zat ini akan mengaktifkan sistem adrenergik pada bagian otak lokus seruleus yang mengeluarkan serotonin. Meningkatnya serotonin menimbulkan rangsangan rasa senang sekaligus keinginan mencari rokok lagi (Gayatri,2012). Secara fisiologis tubuh akan memproduksi serotonin secara autoregulasi. Namun penggunaan nikotin yang menetap menyebabkan disregulasi serotonin, dimana tubuh kesulitan memproduksi serotonin jika kadar nikotin dalam tubuh tidak mencukupi (Benowitz, 2006). Disregulasi dari serotonin ini juga akan meyebabkan gangguan obsesif kompulsif merokok secara biologis. Jadi semakin besar ketergantungan tubuh terhadap nikotin untuk memproduksi serotonin maka akan semakin mempeberat derajat gangguan obsesif kompulsif merokok orang tersebut (Kaplan, 2010).

Rokok adalah silinder dari kertas berukuran panjang antara 70 hingga $120 \mathrm{~mm}$ dengan diameter sekitar $10 \mathrm{~mm}$ yang berisi daun-daun tembakau yang telah dicacah. Rokok dibakar pada salah satu ujungnya dan dibiarkan membara agar asapnya dapat dihirup lewat mulut pada ujung yang lain. ada dua jenis rokok, yaitu berfilter dan tidak berfilter.filter pada rokok terbuat dari busa serabut sintetis yang berfungsi menyaring nikotin (Indri, 2007). Menurut undang-undang no 19 tahun 2003 tentang Pengamanan Rokok Bagi Kesehatan, rokok adalah hasil olahan tembakau terbungkus termasuk cerutu atau bentuk lainnya yang dihasilkan tanaman Nicotiana tobacum, Nicotiana rustica dan spesies lainnya atau sintesis yang mengandung nikotin dan tar dengan atau tanpa bahan tambahan (PPRI. Nomor 19, 2003).

Beberapa teori menarik telah dikembangkan dalam satu dekade terakhir, namun masih belum menemukan hasil yang memuaskan. Kelainan pada sistem saraf yang menjembatani kontrol perilaku (contohnya orbitofrontal dan limbic region) meyebabkan kebiasaan merokok menjadi suatu obsesif kompulsif. Selain itu stimuli yang dibiasakan dalam hal ini adalah kebiasaan merokok yang berulang juga dapat menyebakan gangguan obsesif kompulsif merokok (Brian, 2010). Salah satu kandungan yang terdapat dalam rokok adalah nikotin. Nikotin pada reward system pathways akan memacu sistem dopaminergik. Hasilnya perokok akan merasa lebih tenang,daya pikir serasa lebih cemerlang, dan mampu menekan rasa lapar. Sementara di jalur adrenergik, zat ini akan mengaktifkan sistem adrenergik pada bagian otak lokus seruleus yang mengeluarkan serotonin. Meningkatnya serotonin menimbulkan rangsangan rasa senang sekaligus keinginan mencari rokok lagi.

Nikotin yang terhisap dalam tubuh akan diterima oleh reseptor asetilkolin-nikotinik yang kemudian terbagi ke reward system pathways dan jalur adrenergik. Pada reward system pathways, perokok akan merasa nikmat dan memacu sistem dopaminergik. Hasilnya perokok akan merasa lebih tenang, daya pikir serasa lebih cemerlang, dan mampu menekan rasa lapar. Efek dari nikotin berlangsung sebentar 
saja, oleh karena itu perokok harus terus merokok guna mempertahankan efek sensasi dari nikotin dan untuk menghindar dari gejala putus nikotin. Tetapi bila kadar nikotin turun di dalam darah, perokok akan merasa gelisah, tidak dapat tenang, ini disebut gejala putus nikotin (Nikotin withdrawal). Sementara di jalur adrenergik, zat ini akan mengaktifkan sistem adrenergik pada bagian otak lokus seruleus yang mengeluarkan serotonin. Meningkatnya serotonin menimbulkan rangsangan rasa senang sekaligus keinginan mencari rokok lagi (Gayatri,2012).

Benowitz (2006) bahwa secara fisiologis tubuh akan memproduksi serotonin secara autoregulasi. Namun penggunaan nikotin yang menetap menyebabkan disregulasi serotonin, dimana tubuh kesulitan memproduksi serotonin jika kadar nikotin dalam tubuh tidak mencukupi. Hal ini menyebabkan tubuh akan tergantung pada nikotin untuk memproduksi serotonin. Seseorang yang pertama kali mengkonsumsi rokok biasanya berlanjut menjadi kebiasaan dan akhirnya menjadi ketergantungan. Ketergantungan ini dipersepsikan sebagai kenikmatan yang memberikan kepuasan psikologis. Artinya, kebiasaan merokok merupakan perilaku yang menyenangkan dan bergeser menjadi aktivitas yang bersifat obsesif. Hal ini disebabkan sifat nikotin adalah adiktif, jika dihentikan secara tiba-tiba akan menimbulkan stress (Dian,2006).

WHO menggolongkan kebiasaan merokok sebagai ketagihan. Sekali seseorang menjadi perokok, maka akan sulit mengakhiri kebiasaan itu baik secara fisiologis maupun psikologis. Selain menjadi ketagihan secara fisiologis, merokok juga memenuhi hasrat psikologis yang dirasakan. Proses ini bersamaan dengan menyalakan rokok dan menghembuskannya secara berulang-ulang menjadikan merokok sesuatu yang amat kompulsi (Dian, 2006). Disregulasi serotonin merupakan salah satu penyebab gangguan obsesif kompulsif. Selain itu suatu kebiasaan yang berulang juga merupakan salah satu etiologi dalam pembentukan gangguan obsesif kompulsif . Oleh karena itu dalam hal ini lebiasaan merokok dapat menyebabkan gangguan obsesif kompulsif merokok (Kaplan,2010). Gangguan obsesif kompulsif merokok mempunyai beberapa derajat keparahan. Untuk mengetahui derajat gangguan obsesif kompulsif merokok digunakan kuesioner Obsessive Compulive Smoking Scale (OCSS) (Brian,2010). Didalam OCSS terdapat 10 pertanyaan dan setiap jawaban mempunyai skor yang akan ditotal untuk mengetahui seberapa parah gangguan obsesif kompulsif merokok orang tersebut. Derajat gangguan obsesif kompulsif merokok berdasarkan total skor OCSS adalah skor 0-7yaitu obsesif kompulsif subklinik. Skor 8-15 yaitu obsesif kompulsif ringan. Skor 16-23yaitu obsesif kompulsif sedang. Skor 24-31 yaitu obsesif kompulsif berat. Skor 3240 yaitu obsesif kompulsif sangat berat.

Gejala pasien gangguan obsesif - kompulsif mungkin berubah sewaktu waktu tetapi gangguan ini mempunyai empat pola gejala yang paling sering ditemui, yaitu kontaminasi, keraguan patologis, pemikiran yang mengganggu, simetri. Obsesi akan kontaminasi biasanya diikuti oleh pembersihan atau kompulsi menghindar dari objek yang dirasa terkontaminasi. Objek yang ditakuti biasanya sulit untuk dihindari, misalnya feces, urine, debu, atau kuman. Obsesi ini biasanya diikuti oleh kompulsi pemeriksaan berulang. Pasien memiliki keraguan obsesif dan merasa selalu merasa bersalah tentang melupakan sesuatu atau melakukan sesuatu. Obsesi ini biasanya meliputi pikiran berulang tentang tindakan agresif atau seksual yang salah oleh pasien. Kebutuhan untuk simetri atau ketepatan akan menimbulkan kompulsi kelambanan. Pasien membutuhkan waktu berjam - jam untuk menghabiskan makanan atau bercukur (Kaplan, 2010).

Menurut Sigmund Frued, gangguan obsesifkompulsif bisa disebabkan karena regresi dari fase anal dalam fase perkembangannya (Kaplan, 2010). Mekanisme pertahanan psikologis mungkin memegang peranan pada beberapa manifestasi gangguan obsesif - kompulsi. Represi perasaan marah terhadap seseorang mungkin menjadi alasan timbulnya pikiran berulang untuk menyakiti orang tersebut (Elkin, 2009).

Menurut teori, obsesi adalah stimulus yang terkondisi. Sebuah stimulus yang relatif netral diasosiasikan dengan rasa takut atau cemas melalui proses pengkondisian responden yaitu dengan dihubungkan dengan peristiwa peristiwa yang menimbulkan rasa cemas atau tidak nyaman. Kompulsi terjadi dengan cara yang berbeda. Ketika seseorang menyadari bahwa perbuatan tertentu dapat mengurangi kecemasan akibat obsesif, orang tersebut mengembangkan suatu strategi penghindaran aktif dalam bentuk kompulsi atau ritual untuk mengendalikan kecemasan tersebut. Secara perlahan, karena efikasinya dalam mengurangi kecemasan, strategi penghindaran ini menjadi suatu pola tetap dalam kompulsi (Kaplan, 2010).

\section{Tabel 1. Derajat gangguan obsesif kompulsif merokok berdasarkan total skor OCSS}

\begin{tabular}{ll} 
Skor & Derajat gangguan \\
\hline Skor 0.7 & obsesif kompulsif subllimik \\
\hline Skor 8.15 & obsesif kompulsif rimgan \\
\hline Skor 16.23 & obsesif kompulsif sedang \\
\hline Skor 24.31 & obsesif kompulsif berat
\end{tabular}

(Kaplan, 2010)

Berdasarkan uraian diatas dapat diambil kesimpulan bahwa kebiasaan merokok dapat menyebabkan gangguan obsesif kompulsif merokok. Beberapa teori menarik telah dikembangkan dalam satu dekade terakhir, namun masih belum menemukan hasil yang memuaskan. Kelainan pada sistem saraf yang menjembatani kontrol perilaku (contohnya orbitofrontal dan limbic region) meyebabkan kebiasaan merokok menjadi suatu obsesif kompulsif. Selain itu stimuli yang dibiasakan dalam hal ini adalah kebiasaan merokok yang berulang juga dapat menyebakan gangguan obsesif kompulsif merokok (Brian, 2010). Salah satu kandungan yang terdapat dalam rokok adalah nikotin. Nikotin yang terhisap dalam tubuh akan diterima oleh reseptor asetilkolinnikotinik yang kemudian terbagi ke reward system pathways dan jalur adrenergik. Pada reward system pathways, perokok akan merasa nikmat dan memacu sistem dopaminergik. Hasilnya perokok akan merasa lebih tenang, daya pikir serasa lebih cemerlang, dan mampu menekan rasa lapar. Efek dari nikotin berlangsung sebentar saja, oleh karena itu perokok 
harus terus merokok guna mempertahankan efek sensasi dari nikotin dan untuk menghindar dari gejala putus nikotin. Tetapi bila kadar nikotin turun di dalam darah, perokok akan merasa gelisah, tidak dapat tenang, ini disebut gejala putus nikotin (Nikotin withdrawal). Sementara di jalur adrenergik, zat ini akan mengaktifkan sistem adrenergik pada bagian otak lokus seruleus yang mengeluarkan serotonin. Meningkatnya serotonin menimbulkan rangsangan rasa senang sekaligus keinginan mencari rokok lagi (Gayatri,2012).

Jadi, berdasarkan hasil penelitian ini, diketahui bahwa antara derajat beratnya kebiasaan merokok dengan derajat gangguan obsesif kompulsif merokok pada mahasiswa laki-laki Fakultas Teknik Universitas Muhammadiyah Malang mempunyai keeratan hubungan yang signifikan, dimana beratnya derajat gangguan obsesif kompulsif akibat merokok berbanding lurus dengan derajat beratnya gangguan obsesif kompulsif. Bagi masyarakat yang mempunyai kebiasaan merokok untuk segera melakukan pemeriksaan dini untuk mencegah terjadinya gangguan obsesif kompulsif yang lebih berat. Selain itu, hendaknya juga diupayakan untuk sedikit demi sedikit mengurangi jumlah rokok yang dihisap, dengan tujuan agar dapat terlepas dari ketergantungan pada rokok yang sangat membahayakan bagi kesehatan perokok itu sendiri maupun bagi orang-orang di sekitarnya yang turut menjadi perokok pasif.

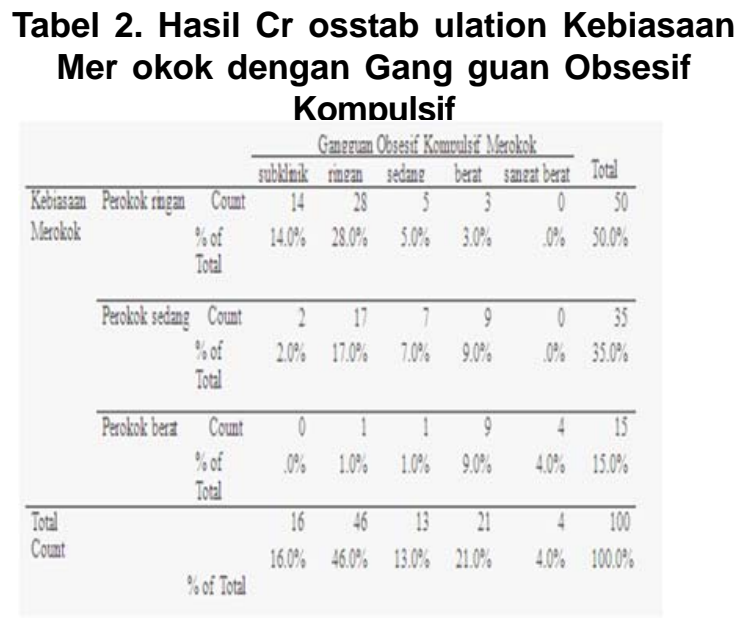

(Data primer yang diolah, 2012)
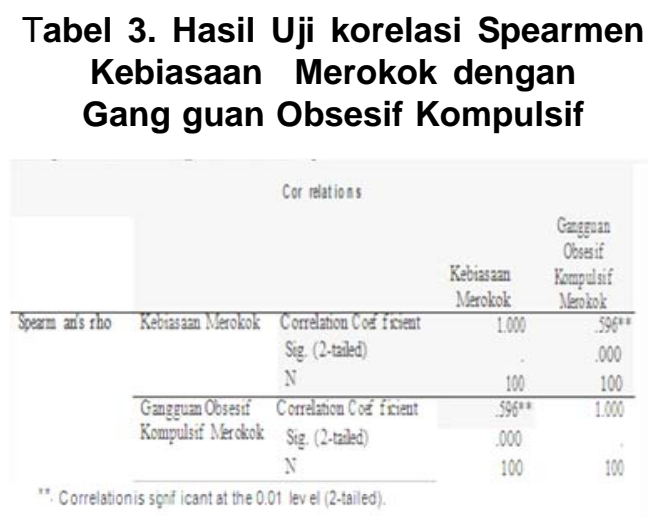

(Data primer yang diolah, 2012)

\section{SIMPULAN}

Kesimpulan berdasarkan hasil penelitian yang telah dilakukan adalah para mahasiswa laki-laki Fakultas Teknik Universitas Muhammadiyah Malang lebih banyak yang tergolong sebagai perokok ringan (50\%). Kesimpulan kedua yang didapatkan adalah para mahasiswa laki-laki Fakultas Teknik Universitas Muhammadiyah Malang lebih banyak yang mengalami gangguan obsesif kompulsif merokok dalam skala yang ringan (46\%). Hal lain yang didapatkan adalah ada korelasi yang signifikan (bermakna) antara derajat beratnya kebiasaan merokok dengan derajat gangguan obsesif kompulsif merokok pada mahasiswa laki-laki Fakultas Teknik Universitas Muhammadiyah Malang (dengan nilai $\mathrm{p}<\alpha 0.05$ ).

\section{DAFTAR PUSTAKA}

Benowitz, N. L. (2008). Neurobiology of Nicotine Addiction: Implications for Smoking Cessation Treatment. The American Journal of Medicine vol 121 (4a), S3-S10.

Brian, H et al. (2010). Measuring Smoking-related preoccupation and compulsive drive: evaluation of the obsessive compulsive smoking scale. Psychopharmacology, vol 211:377-387.

Dian K., Avin F. (2006). Faktor-Faktor Penyebab Kebiasaan Merokok Pada Remaja. Universitas Gadjah Mada, Jogjakarta.

Doe jen, D.C. (2009). The Risk of Tobacco Use. Journal of American Academy of Pediatrics, Georgetown.

Elkin GD. (1999). Obsessive compulsive disorder: Introduction to Clinical Psychiatry. $1^{\text {st }} \mathrm{ed}$. Appleton \& Lange, 45, 95-98.

Fernando, E. (2011). Analisa Kandungan Nikotin pada Tembakau (Nikotiana tobacum) yang digunakan sebagai Tembakau Kunyah dan Karakteristik Masyarakat Penggunanya di Desa Rumah Gerat Kecamatan Biru-Biru Kabupaten Deli Serdang tahun 2010. Universitas Sumatera Utara, Medan.

Ganong, W.F. (2008). Buku Ajar Fisiologi Kedokteran. Jakarta : EGC.

Gayatri A., Susanto A.D. \& Setiawati A. (2012). Nicotine Replacement Therapy. CDK-189, 39(1), 25-30.

Gondodiputro, S. (2007). Babaya Tembakau dan Bentuk-Bentuk Sediaan Tembakau. Universitas Padjajaran, Bandung.

Heatherton TF, Kozlowski LT, Frecker RC, Fagerstrom KO. (1991). The Fagerstrom Test for Nicotine Dependence: A revision of the Fagerstrom Tolerance Questionnaire. British Journal of Addictions 1991;86:1119-27.

Heyman I. (2006). Obsessive compulsive disorder. BMJ vol $333: 424-429$.

Indri, K.N. (2007). Perilaku Merokok Pada Remaja. Fakultas Kedokteran Universitas Sumatera Utara, Medan.

Irawan. (2009). Faktor-Faktor Yang Berpengarub Terhadap Daya Tahan Jantung Paru, Universitas Muhammadiyah Surakarta, Surakarta.

James, W.K. (2009). Biological Psychology. Tenth ed. Wadsworth Publishing, USA: James W. Kalat: 343-376. 
Jenike MA. (2004). Obsessive compulsive disorder. N Eng $J$ Med , 350, 259-265. Jha, P. \& Chaloupka, F.J. (2000). Meredam Wabah : Pemerintah dan Aspek Ekonomi Pengawasan Terhadap Tembakau. Washington : The World Bank.

Jusuf, Anwar et al. (2002). Hubungan Merokok Kretek Dengan Kanker Paru. Jurnal Respirologi Indonesia, 22 :109-125.

Maramis. (2004). Catatan Ilmu Kesehatan Jiwa. Surabaya : Airlangga Press.

Mulcahy, S. (1997). The Toxicology of Cigarette smoke and Environment Tobacco Smoke. New York : Biochemical Toxicology. Available at : www.csn.ul.ie/ stephen/ reports/bc4927.html.

Peraturan Pemerintah Republik Indonesia, Nomor 19 Tahun 2003, „Pengamanan Rokok Bagi Kesehatan’.

Pradono. K. (2002). Perokok Pasif Bencana Yang Tak Terlupakan. Badan Penelitian dan Pengembangan Kesehatan Dinkes, Jakarta. pp. 1-13.

Raka, M.S., Frieda, NRH. \& La Kahija, Y. F. (2010). Stop Smoking! Studi Kualitatif Terhadap Pengalaman Mantan Pecandu Rokok dalam Menghentikan Kebiasaannya. Semarang: Universitas Diponegoro.

Saddock BJ, Saddock VA. (2003). Obsessive-Compulsive Disorder. Dalam : Kaplan \& Sadock's Synopsis of Psychiatry, ninth ed. Lippincott Williams \& Wilkins, Philadelphia. h 616-23.

Stein, DJ. (2002). Obsessive compulsive disorder. Lancet, $360,397-405$.

Taylor,C. (2009). Obsessive compulsive disorder. InnovAiT. 2009, 2, 358 - 363. Tjandra, Y.A. et al. (2006). Global Youth Tobacco Survey. Jakarta : UI Press.

World health Organization (WHO). (2003). Konsumsi Tembakau dan Perilaku Merokok di Indonesia. Diakses pada tanggal $27 \quad$ November 2010. Available at : http://www.who.int/icd/orh/index.html.

World health Organization (WHO). (2003). WHO Framework Concention on Tobacco Control. Geneva : World Health Organization. Available at http://www.who.int/ tobacco/framework. 